\title{
Morphological structure and body indices for Bunaji and Friesian-Bunaji crosses
}

\author{
Alphonsus, C.
}

Animal Science Department,

Kaduna State University, Kafanchan Campus, Nigeria,

Correspondent author: Cyprian.alphonsus@kasu.edu.ng 07035595978

Abstract

The objective of this study was to provide information on the morphological structure and body indices of Bunaji cattle and their crosses. Body weight and eight (8) morphological traits of 72 Bunaji and 60 Friesian x Bunaji cows were measured. The morphological parameters were used to calculate nine body indices. The analyzed morphological traits showed that the crossbred cows were heavier with larger morphological structure than the pure breed; however, both animals slightly slope forward although not very unbalanced. The correlation coefficients amongst the morphological traits in Bunaji were all positive and significant $(P<0.05-0.01)$ except for correlation of Rump Width $(R W)$ with Body Depth (BD: $r=0.352)$ and Body Length (BL: $r=0.210)$. However, the correlation coefficients amongst the morphological traits in the crosses were generally weak. The strongest correlation was observed between $B W$ and $H G(0.926)$ and between $B W$ and $R W(r=0.946)$ in Bunaji and their crosses, respectively. The Principal Component Analysis (PCA) of the morphometric traits extracted one component with total variance of $67.67 \%$ in Bunaji and two components with total variance of $74.30 \%$ in the crosses. The first factor in each case had higher loadings for variables relating to body size, while the second $P C$ in the crosses had high association with traits that reflect the body shape of the animal. The HG and RW were the single most informative morphological traits for estimation of $B W$ in Bunaji and Friesian x Bunaji, respectively. In Conclusion, the Bunaji cattle are medium size animals, although they are used for both meat and milk production (multipurpose) there morphology showed some resemblance to milk type animal, thus suggesting a possible genetic improvement of these animals for dairy purpose.

Keywords: Friesian-Bunaji cross, Principal component analysis, morphometric, index

\section{Introduction}

According to Tawah and Rege (1996), the White Fulani (Bunaji) cattle are the most numerous and wide spread of all the Nigerian cattle breeds. They represent about $37 \%$ of the National cattle population in Nigeria and are mainly own by the Nomadic Fulani people who occupy the belt between the Sahara and the coastal rainforest from the west of the river Senegal to the east of Lake Chad, including parts of Southern Mauritania, Northern Nigeria and Cameroon.

In Nigeria, Friesian sires are the most predominant dairy breed of cattle used in upgrading the milk production of the Bunaji cows. This has produced a stabilized crossbred. However, very few information is available on the morphological structure and body indices of this indigenous cattle and their crosses.

The development of skill to visually appraise cattle and subsequently evaluate condition that contributes to herd productivity has traditionally been a key to successful cattle breeding. However, emphasis had shifted from subjective method of appraising cattle to a more objective method like the used of linear measurement of body parts (Essien and Adesope, 2003).

Weight measurement has been accepted as 


\section{Morphological structure and body indices for Bunaji and Friesian-Bunaji crosses}

an objective measurement of growth, however due to the cost in procuring the weighing equipment especially for large animals, attempts have been made to develop method for estimating weight with the use of linear body measurements (Orheruata and Olutogun, 1994, Akpa et al., 1998; Alade et al., 1998). Desirable body conformation from the meat and milk production view point is such a complex character that little progress has been made in reducing it to a single corporal measurement which can be taken on the live animal. However, with the introduction of indices from body measurements, objective assessment of body conformation may be easier. Body indices are considered a good option for weight assessment because they incorporate measures of desirable conformation such as length and balance (Alderson, 1999). They are often used to draw some conclusions concerning proportionality and maturity of the animals, especially when taken with some other traits such as live weight. Therefore, the objective of this study was to provide information on the morphological structure and body indices of Bunaji cattle and their crosses.

\section{Materials and methods \\ Studylocation}

Phenotypic measurements were taken on 72 Bunaji and 60 Friesian x Bunaji cows at National Animal Production Research Institute (NAPRI), Sahika, Zaria, located on latitude $11^{\circ} 12^{\prime} \mathrm{N}$ and $7^{\circ} 34^{\prime} \mathrm{E}$, at an altitude of $640 \mathrm{~m}$ above sea level, and lies within the Northern Guinea Savannah Zone of Nigeria (Malau-Aduli and Abubakar, 1992). The cows were raised under semiintensive management system whereby they were grazed during the rainy season on both natural and paddock sown pasture, while hay and/ or silage were offered during the dry season.

\section{Ethical clearance}

Since the study did not involve any invasive or painful procedure to the animals, ethical approval was not sought, however the guidelines and procedures for the use of animals in the institute (National Animal Production Research Institute) where the research was conducted was strictly followed.

\section{Data collection}

Eight morphological traits comprised of Rumps Height (RH), Chest Width (CW), Withers Height (WH), Heart Girth (HG), Body Length (BL), Body Depth (BD) Rump Width (RW) and Body Weight (BW) were measured. The morphological traits were measured in centimeter $(\mathrm{cm})$ using calibrated measuring pole and flexible metric tape, while the body weight was measured using weighbridge (model: Avery weighbridge Birmingham England, $500 \mathrm{~kg}$ ). Pregnant animals were not included in the study because of the effect of pregnancy on weight and shape of the animal, also only matured cows of not less than four years were used for the study. All the morphological measurements were taken with the animals standing on a flat surface in a tight stall with the head held up. To reduce the errors, measurements were taken two or three times in each animal. The eight original morphological variables measured were used to calculate nine body indices (Table 1). The details of the measurements and definition of the traits has earlier been described by Alderson (1999) and Alphonsus et al. (2009).

\section{Statistical analysis}

The data were analyzed using descriptive statistics and Analysis of Variance of fixed effect of breed on the morphological characteristics was done using Univariate Analysis of General Linear Model procedure of SAS (1999). Principal component analysis (PCA) was applied separately to 8 morphological 


\section{Alphonsus}

Table 1: Detail calculation of body indices (Alderson 1999; Sarma 2006)

\begin{tabular}{|c|c|c|c|}
\hline & Measurements & Abbrev & Description \\
\hline 1 & Height slope & HS & Withers height - rumps height \\
\hline 2 & Width slope & WS & Rumps width/ chest width \\
\hline 3. & Length index & LI & Body length / withers height \\
\hline 4 & Depth index* & DI & Body depth/withers height \\
\hline 5 & Foreleg length* & FL & Withers height- body depth \\
\hline 6 & Body index & BI & (Body length/heart girth)x 100 \\
\hline 7 & Height index & $\mathrm{HI}$ & Withers height/body length \\
\hline 8 & Weight index & WI & Body weight $\mathrm{x}$ withers height \\
\hline 9 & Body & IB & $\begin{array}{l}\text { Body length } x \text { 100/Heart girt; when IB > } \\
0.90 \text { the animal is longiline; between } 0.86 \\
\text { and } 0.88 \text { is medigline, and } 1 \text { ess than } 0.85 \text { is } \\
\text { brevigline (Chacon et al., 2011) }\end{array}$ \\
\hline
\end{tabular}

measurements of Bunaji and Friesian $\mathrm{x}$ Bunaji cows. The PCA was used to reduce the dimensionality of the morphological measurements into few uncorrelated components (PCs). Varimax orthogonal rotation was applied to enhance the interpretability of the principal components.

\section{Results and discussion}

The means and standard error (SE), standard deviation (SD) and coefficient of variability $(\mathrm{CV})$ of each trait as well as the significance of breed differences between Bunaji and their crosses are presented in Table 2. Body weight was the most variable body measurement as indicated by the $\mathrm{CV}$ of $18.65 \%$ and $12.53 \%$ for Bunaji and their crosses, respectively. The other morphological traits showed high homogeneity in both Bunaji (CV ranges from $2.53 \%$ to $6.57 \%$ ) and their crosses (CV ranges from $1.00 \%$ to $2.97 \%$ ). The Friesian genes had significant effect $(\mathrm{P}<$ 0.05- 0.01) on the weight and morphology of the crosses, thus the crosses had larger body capacity than the pure Bunaji; the crosses were taller (RH: $132.8 \mathrm{~cm}$; WH: 129.12cm), broader (CW: 25.83cm; HG: $175.17 \mathrm{~cm}$ ), longer (BL: $124.52 \mathrm{~cm})$ and heavier (BW: $409.07 \mathrm{~kg}$ ) than the pure breed. Large body capacity is associated with ample space for the rumen and digestive system, and this in turn, is associated with superior milk production. Dairy cow with little body capacity cannot be good milk producer; this is because the gut size is limited by the capacity of the abdominal cavity. This partly explains why the crosses had higher milk production than the pure Bunaji.

The Friesian sires which are large dairy breed were used to crossbreed the Bunaji cows for increase milk production. The main income for the breeders from these crossbred animals is from the sales of the milk, while the Bunaji are multipurpose breed. Therefore, conformation and weight evaluation are important factors especially because of its health and management implication. Body weight is an important functional trait regulating feed efficiency and energy balance in both beef and dairy cattle (Sondergrard et al., 2002). Also apart from its wide use in measuring responses to 


\section{Morphological structure and body indices for Bunaji and Friesian-Bunaji crosses}

impose treatments, BW provides criteria against which other variable may be set and correlated with (Lawrence and Fawler,
1998). Therefore, adequate knowledge of correlated traits that can be considered when selection is to be applied for BW in either dairy or beef cattle is required.

Table 2: Descriptive statistics of morphological traits in matured Bunaji cows and their crosses

\begin{tabular}{llllllll}
\hline \multirow{2}{*}{ Traits } & \multicolumn{2}{l}{ Bunaji $(\mathrm{n}=72)$} & \multicolumn{4}{c}{ Friesian $x$ Bunaji crosses $(\mathrm{n}=60)$} & Breed \\
\cline { 2 - 7 } & Means \pm SE & SD & CV $(\%)$ & Means \pm se & SD & CV & differences \\
\hline BW $(\mathrm{kg})$ & $379.39 \pm 7.04$ & 59.75 & 18.65 & $409.07 \pm 6.31$ & 48.89 & 12.53 & $29.68^{* *}$ \\
ST $(\mathrm{cm})$ & $128.06 \pm 0.59$ & 5.02 & 3.92 & $132.67 \pm 0.26$ & 2.07 & 1.61 & $4.61^{* *}$ \\
CW $(\mathrm{cm})$ & $21.83 \pm 5.02$ & 1.43 & 6.57 & $25.83 \pm 0.09$ & 0.69 & 2.68 & $4.00^{* *}$ \\
BD $(\mathrm{cm})$ & $107.00 \pm 0.49$ & 4.20 & 4.16 & $105.33 \pm 0.37$ & 2.89 & 2.97 & -1.67 \\
HW $(\mathrm{cm})$ & $125.06 \pm 0.60$ & 5.09 & 4.07 & $129.50 \pm 0.16$ & 1.27 & 1.00 & $4.44^{* *}$ \\
HG $(\mathrm{cm})$ & $172.78 \pm 1.17$ & 9.90 & 5.73 & $175.67 \pm 0.29$ & 2.30 & 1.31 & $2.89^{*}$ \\
BL $(\mathrm{cm})$ & $121.56 \pm 0.35$ & 3.03 & 2.53 & $124.17 \pm 0.34$ & 2.63 & 2.13 & $2.61^{*}$ \\
RW $(\mathrm{cm})$ & $18.50 \pm 0.10$ & 0.84 & 4.77 & $17.56 \pm 0.07$ & 0.50 & 2.88 & 0.94 \\
\hline$*=\mathrm{P}<0.05 * * * 0.01$ & & & & & & &
\end{tabular}

Body indices are relationship among body measurements that are used to describe the proportion and general size of the body parts of animals. In this study the indices (Table 3) suggested that the Bunaji and their crosses are not Mesomorphic as their body length was lower than the withers height. The height slope showed that both animals stood slightly higher at the rump (RH) than the withers (HW), this make the animals to slightly slope forward although not very unbalanced. (Chacon et al., 2011). The body index which is used to determine the animal's proportion was similar in both the Bunaji (70.36) and their crosses (70.68). Usually, there should be a balance between the height, body length and heart girth of the animals since imbalance in its gravity center may affect its ability to balance on the ground. Most of the indices did not showed significant differences between the Bunaji and the crosses except foreleg length (FL), height index (HI) and weight index (W).

Table 3: Body indices of Bunaji and Friesian $x$ Bunaji cows

\begin{tabular}{llll}
\hline Body indices & Bunaji & Friesian $x$ Bunaji & Differences between means \\
\cline { 2 - 3 } & Means \pm SE & Means \pm SE & \\
\hline Height slope & $-3.00 \pm 0.18$ & $-3.17 \pm 0.47$ & -0.17 \\
Width slope & $0.85 \pm 0.10$ & $0.68 \pm 0.01$ & 0.17 \\
Length index & $0.97 \pm 0.08$ & $0.95 \pm 0.01$ & 0.02 \\
Depth index & $0.86 \pm 0.01$ & $0.81 \pm 0.01$ & .0 .05 \\
Foreleg length & $18.08 \pm 0.84$ & $24.17 \pm 0.98$ & $-6.09^{* *}$ \\
Body index & $70.36 \pm 0.75$ & $70.68 \pm 0.44$ & -0.32 \\
Height index & $3.50 \pm 0.01$ & $1.04 \pm 0.01$ & $2.46^{*}$ \\
Weight index & $47446.51 \pm 2204$ & $52974 \pm 565$ & $-5528^{* *}$ \\
Body & $70.36 \pm 0.14$ & $70.68 \pm 0.11$ & -0.32 \\
\hline
\end{tabular}

$*=\mathrm{P}<0.05 ; * * \mathrm{P}<0.01$

The correlation coefficients amongst the morphological traits (Table 4) were relatively stronger in Bunaji than the crosses; all the correlation coefficients in Bunaji were significantly $(\mathrm{P}<0.05-0.01)$ positive except the correlation of RW with $\mathrm{BD}(\mathrm{r}=0.352)$ and $\mathrm{BL}(\mathrm{r}=0.210)$. This indicates a high level of dependency and multicollinearity amongst the morphological traits of Bunaji, thus it may 


\section{Alphonsus}

not be necessary to incorporate all these traits in the development of selection index aim at improving the performance of the animals. This is so because selection for the improvement in one trait will results in a correlated response in the other traits (Wattiaux, 2002; De Haas et al., 2007). However, the magnitude of the correlations amongst the morphological traits in the crosses was weak and varied in direction except the correlations between BW and ST $(\mathrm{r}=0.541), \mathrm{BW}$ and RW $(\mathrm{r}=0.945)$, ST and BD $(r=0.76)$, ST and HW $(r=0.902)$ and ST and RW ( $r=0.649)$ which were strong. Also the correlations between BD and HW $(\mathrm{r}=0.693), \mathrm{BD}$ and $\mathrm{HG}(\mathrm{r}=0.500)$ and $\mathrm{HG}$ and $\mathrm{BL}(\mathrm{r}=0.764)$ were significantly strong and positive $(\mathrm{P}<0.05-0.001)$. Worthy of note is the strong positive relationship of BW with HG (0.926) and RW $(r=0.946)$ observed in Bunaji and their crosses, respectively. This suggested that these two morphological traits (HG and RW) can be very effective in predicting $\mathrm{BW}$ and their selection in breeding programme may results in remarkable body weight improvement. The fact that the conformation traits are highly heritable (De Haas et al., 2007; Alphonsus et al., 2010) and can often be recorded in a single assessment, makes them cheaper and more practicable to measure in the field than BW (especially in larger animals like cattle), may justify their inclusion in a selection index for BW improvement.

Table 4: correlation coefficients amongst morphometric traits of Bunaji (upper) and their crosses (lower)

\begin{tabular}{|c|c|c|c|c|c|c|c|c|}
\hline \multirow[t]{2}{*}{ Traits } & \multicolumn{8}{|c|}{ Bunaji cows } \\
\hline & BW & ST & CW & BD & HW & $\mathrm{HG}$ & $\mathrm{BL}$ & RW \\
\hline BW & - & $0.841^{* *}$ & $0.678^{* *}$ & 0.790 ** & $0.876^{* *}$ & $0.926^{* *}$ & $0.659 * *$ & $0.666^{* *}$ \\
\hline ST & $0.541 *$ & - & $0.643^{* *}$ & $0.731^{* *}$ & $0.989 * *$ & $0.790 * *$ & $0.536^{*}$ & $0.596^{*}$ \\
\hline $\mathrm{CW}$ & -0.095 & 0.078 & - & 0.299 & $0.657^{* *}$ & $0.624 * *$ & $0.424 *$ & $0.641 * *$ \\
\hline BD & 0.226 & $0.726^{* *}$ & -0.141 & - & $0.735^{* *}$ & $0.719 * *$ & $0.598 *$ & 0.352 \\
\hline HW & 0.202 & $0.902 * *$ & -0.096 & $0.693^{* *}$ & - & $0.832 * *$ & $0.524 *$ & $0.639 * *$ \\
\hline $\mathrm{HG}$ & -0.055 & 0.012 & 0.389 & $0.500^{*}$ & -0.174 & - & $0.634 * *$ & $0.633^{* *}$ \\
\hline BL & 0.173 & 0.196 & $0.480 *$ & 0.394 & -0.025 & $0.764 * *$ & - & 0.210 \\
\hline RW & $0.946^{* *}$ & $0.649^{* *}$ & -0.243 & 0.349 & 0.397 & -0.146 & 192 & - \\
\hline
\end{tabular}

Table 5 showed the summary of principal components analysis (PCA) and the loading pattern of the morphological measurements on the principal components (PCs) after a varimax rotation. The loadings pattern showed the relative contribution of each measurement to a particular PC, whilst the percentage of the total variance is used as an index to determine how well the total components extracted account for what the variable (measurement) together represents. Therefore, PCA determines the variability of individual traits and how these contribute toward the total morphological and structural variance of the animals (Mavule et al., 2013).

In Bunaji, all the variables were grouped into one PC with Eigen value of 4.74 accounted for a total variance of $67.67 \%$. All the variables measured had high positive loadings on a single PC. This suggested that the morphological variables measured in Bunaji can be reduced into one composite variable without losing much of the information. However, in the crosses two PCs were extracted and accounted for $74.30 \%$ of the total variance. The first PC explained $42.98 \%$ of the total variance and 
was characterized by relatively high positive loadings for ST, BD, HW and RW. The second $\mathrm{PC}$ had high loadings for $\mathrm{CW}$, HG and BL explaining $31.32 \%$ of the total variance. The communality estimates (the proportion of common variance present in a variable) for all the morphological measurements range from $49.91(\mathrm{RW})$ to 90.61\% (HW) in Bunaji and 46.31\% (CW) to $92.26 \%$ (ST) in the crosses. The percentage of variance explained by the PCA in Bunaji (67.67\%) and the crosses (74.30\%) were lower than those reported by Yakubu et al. (2009) in young (78.99\%) and adult $(86.47 \%)$ cattle. This is an indication that more morphological variations were left unexplained in the present study probably because of the wide ranges in the ages of the population of animals used. The remaining unexplained variance could be attributed to segregation of casual alleles at contributory loci, measurements error and environmental factors influences especially on the measurements that are not so close to the bone structure of the animals (Chacon et al., 2011; Alphonsus et al., 2012; Mavule et al., 2013). The morphological measurements (ST, HW,
$\mathrm{BL}, \mathrm{BD})$ loaded heavily on PC1 in both the Bunaji and the crosses and are associated with bone structure and body size of the animals, while the measurement $\mathrm{CW}, \mathrm{HG}$, and RW loaded heavily on the second $\mathrm{PC}$ in the crosses and are good descriptors of body shape, and could be significantly influenced by nutritional and other environmental factors (Alphonsus et al., 20112). The muscle fat along with bone structure contributes to their formation (Mavule at al., 2013).

The current study also revealed that each PC is an association of related morphometric traits defining certain body dimension of the animals. That is PC1 and PC2 define body size and shape, respectively and since PCs are orthogonal and uncorrelated with each other, body size is independent of the shape in the crosses. However, in the pure Bunaji cow, size and shape are dependent on each other. The variation in the number of PCs extracted in Bunaji and their crosses could be attributed to differences in type and function of the animals; the Bunaji are unspecialized multipurpose breeds used for beef, milk and draught, while the crosses are milk animals.

Table 5: Eigen values, share of total variance along with factor loadings after varimax rotation and communalities of the morphological measurements of Bunaji and their crosses

\begin{tabular}{llllll}
\hline Traits & Bunaji & \multicolumn{3}{c}{ Friesian x Bunaji cows } \\
\cline { 2 - 6 } & CP1 & Communality & CP1 & CP2 & Communality \\
\hline Stature (ST) & 0.94 & 87.54 & 0.96 & 0.07 & 92.26 \\
Chest width (CW) & 0.74 & 55.03 & 0.17 & 0.66 & 46.31 \\
Body depth (BD) & 0.78 & 60.99 & 0.82 & 0.36 & 79.86 \\
Height at withers (HW) & 0.95 & 90.61 & 0.90 & -0.14 & 82.54 \\
Heart girth (HG) & 0.92 & 84.32 & 0.02 & 0.92 & 85.43 \\
Body length (BL) & 0.67 & 45.22 & 0.19 & 0.89 & 82.96 \\
Rumps width (RW) & 0.71 & 49.91 & 0.70 & -0.13 & 50.75 \\
Eigen value & 4.74 & & 3.01 & 2.19 & \\
\% of variance & 67.67 & & 42.98 & 31.32 & \\
Cumulative variance & 67.67 & & 42.98 & 74.30 & \\
\hline
\end{tabular}


Conclusion

The Bunaji cattle are medium size animals, used for both meat and milk production, there morphology showed some resemblance to milk type animal. This suggests a possible genetic improvement of these animals for dairy purpose. Crossbreeding of Bunaji cows with Friesian sires resulted in larger morphological structure of the crosses and conformation that is similar to dairy type animals.

\section{Acknowledgements}

The Author wish to thank the Director, National Animal Production Research Institute (NAPRI), Ahmadu Bello University, Zaria-Nigeria, for given me the animals and facilities used for this research and the technical staff also who assisted in the collection of the data.

\section{References}

Tawah, C. L. and Rege, J. E. O 1996. White Fulani cattle of west and central Africa, FAO. Animal Genetic Resources information. 17:137-158

Essien, A. and Adesope, O. M. 2003. Linear body measurements of N'dama calves at 12 month in South Western zone of Nigeria. Livestock Research for Rural Development, 15: 4-9

Orheruata, A. M. and Olutogun, O. 1994. Pre-and post-weaning phenotypic relationship between some N'Dama cattle linear measurement in the tropics. Nigeria Journal of Animal Production, 21:76-82.

Akpa, G. N., Duru, S. and Amos, T. T. 1998. Influence of strain and sex on estimation of within-age-group body weight of Nigerian Maradi goats from their linear body measurement. Tropical Agriculture (Trinidad) 4:462-467

Alade, N. K., Olutogun, O. and Igwebuike, J. U. 1999. Genetic characterization of linear measurement of $N^{\prime}$ dama cattle of various ages in the humid tropics. Proceedinggs of $2^{\text {th }}$ annual conference of Nigerian Society for Animal Production (NSAP). 21-15 March 1999. Pp.315-318

Alderson, G. L. H. 1999. The development of a system of linear measurements to provide an assessment of type and function of beef cattle. AGRI 25:45-55

Malau-Aduli, A. E. O. and Abubakar, B. Y. 1992. Estimation of 305-day yield from milk yield in Bunaji and Friesian-Bunaji crosses. Nigeria Journal of Animal Production, 19(182):141-143

Alphonsus, C., Akpa, G. N. and Oni, O. O. 2009. Repeatability of objective measurements of linear udder and body conformation traits in Frisian x Bunaji cows. Animal Production Research Advances. African Journal Online (AJOL). 5(4):224-231

SAS 1999. Statistical Analysis System Procedure guide for Personal computers. SAS Institute Inc. Cavy, North Carolina.

Sondergaard, E., Sorensen, M.K., Mao, I. L. and Jensen, J. 2002. Genetic parameters of production feed intake, body weight, body composition and udder health of lactating dairy cows. Livestock Production Science, 77:23-3

Lawrence, T. I. J. and Fowler, V. R. 1998. Growth on farm animals. CAB International Wallingford, UK

Chacon, E., Macedo, F., Velazquez, F., 
Paiva, S. R., Pinede, E. and M c m a n u s, C. 2011 . Morphological measurements and Body indices for Cuban creole goats and their crossbreds. Revista Brasileira de Zootecnia 40(8):1671- 1679

Wattiaux, M. 2002. Technical dairy guide: Reproduction and genetic selection. The Babcock Institute for International Dairy Research and Development, University of Wisconsin

De Haas, Y., Janss, L. K. G. and Kadarmideen, H. N. 2007. Genetic and phenotypic parameters for conformation and yield traits in three dairy cattle breeds. Journal of Animal Breeding and Genetics, 124(1): 12 -19 .

Alphonsus, C., Akpa, G. N., Oni, O. O., Rekwot, P. I. and Barje, P. P. 2010. Relationship of linear conformation traits with bodyweight, body condition score and milk yield in Friesian X Bunaji cows. Journal of Applied Animal Research. Taylor and Francis, Publ, 38: 97-100

Mavule, B. S., Muchenje, V., Bezuidenhout, C. C. and Kune ne, N. W. 2013 . Morphological structure of Zulu sheep based on principal component analysis of body measurements. Small Ruminant Research 111:23-30

Yakubu, A., Ogah, D. M. and Idahor, K. O. 2009. Principal component analysis of the morphostructural indices of White Fulani cattle. Trakia Journal of Science. 7:67-73

Alphonsus, C., Akpa, G. N., Kpanja, E. J., Finangwai, I. H. and Byanet, O. 2012. Genetic and non-genetic sources of Variation for Linear body Conformation Traits in Bunaji and Friesian X Bunaji cows. Agrosearch Faculty of Agriculture, University of Ilorin, Ilorin, Nigeria. 12 (1):51-60

Heinrichs, A. J., Erb. Rogers, G. W., Cooper, J. B. and Jones, C. M. 2007. Variability in Holstein heifers heart girth measurements and comparison of Prediction equations for live weight. Preventive Veterinary Medicine 78 (3): 333-338.

Mantysaari P 1996: Predicting body weight from body measurements of pre-pubertal Ayrshire heifers. Agric. Food Science, Finland. 5:17-23.

Nsoso, S. J., Aganga, A. A., Moganetsi, B. P. and Tshwenyane, S. O. 2003. Body weight, body condition score and heart girth in indigenous Tswana goats during the dry and wet seasons in Southeast Botswana. Livestock Research for Rural development 4 (15):1-6

Received: $6^{\text {th }}$ September, 2018 Accepted: $21^{\text {st }}$ December, 2018 